\title{
Experimental Study on Heat Transfer Characteristics of R134a Flow Boiling in “ $\Omega$ ”-shaped Grooved Tube with Different Flow Directions
}

\author{
Wen-Long Cheng ${ }^{1, *}$, Hua Chen ${ }^{1}$, Shuai Yuan ${ }^{1, *}$, Qi Zhong ${ }^{2,3}$, Yu-Feng Fan ${ }^{2}$
}

\begin{abstract}
To study the heat transfer enhancement of flow boiling in " $\Omega$ "-shaped grooved tube, an experimental investigation with refrigerant R134a as working fluid was conducted. The experiments were performed at different flow directions with mass flux of $10-30 \mathrm{~kg} /\left(\mathrm{m}^{2} \cdot \mathrm{s}\right)$ and heat flux of $3-10 \mathrm{~kW} / \mathrm{m}^{2}$, respectively. The effects of vapor quality, heat flux and mass flux in horizontal, upward and downward flow were compared and analyzed. The comparative study with smooth tube showed significant enhancement of 1.5-3.3 times on heat transfer coefficient in horizontal and upward flow. Contrary to smooth tube results, heat transfer coefficient of downward flow is much higher than horizontal flow. The comparative study between different flow directions showed that heat transfer coefficient decreased with increasing vapor quality in horizontal and downward flow, however in upward flow, it was almost constant. In horizontal and upward flow, heat flux showed a strong positive effect and the effect of mass flux was not very sensitive; however in downward flow, heat flux showed a negative effect and mass flux showed a stronger positive effect. It is concluded that the effect mechanism of gravity on heat transfer in " $\Omega$ "-shaped grooved tube is quite different from smooth tube and heat transfer enhancement caused by " $\Omega$ "-shaped grooves is not only because of the increase in inner surface area. What's more, heat transfer is dominated by nucleate boiling in horizontal and upward flow, while in downward flow, convective boiling comes to dominate.
\end{abstract}

Keywords: flow boiling; heat transfer enhancement; " $\Omega$ " shaped groove; flow direction; two phase 


\section{Nomenclature}

$31 \quad A_{\mathrm{i}} \quad$ inner flow area, $\mathrm{m}^{2}$

$32 \quad c_{\mathrm{p}, \mathrm{f}} \quad$ specific heat capacity, $\mathrm{J} /(\mathrm{kg} \cdot \mathrm{K})$

$33 C_{\mathrm{i}} \quad$ inner circumference, $\mathrm{m}^{2}$

$34 \quad D \quad$ diameter of tube, $\mathrm{m}$

$35 \quad d \quad$ diameter of groove, $\mathrm{m}$

$36 \quad G \quad$ mass flux, $\mathrm{kg} /\left(\mathrm{m}^{2} \cdot \mathrm{s}\right)$

$37 h_{\mathrm{fb}} \quad$ heat transfer coefficient, $\mathrm{W} /\left(\mathrm{m}^{2} \cdot \mathrm{K}\right)$

$38 \quad h_{\mathrm{fg}} \quad$ latent heat of vaporization, $\mathrm{J} / \mathrm{kg}$

$39 k$ thermal conductivity, $\mathrm{W} /(\mathrm{m} \cdot \mathrm{K})$

$40 \quad L \quad$ length of test tube, $m$

$41 \quad n \quad$ number of grooves

$42 \quad P \quad$ heating power, $\mathrm{W}$

$43 q$ heat flux, $\mathrm{W} / \mathrm{m}^{2}$

$44 \quad Q \quad$ volumetric flow rate, $\mathrm{m}^{3} / \mathrm{s}$

$45 \quad R \quad$ thermal resistance, $\mathrm{K} / \mathrm{W}$

$46 \quad T \quad$ temperature, $\mathrm{K}$

$47 \quad w \quad$ width of groove channel, $\mathrm{m}$

$48 \quad x \quad$ vapor quality

49

$50 \quad$ Greek letters

$51 \rho_{\mathrm{f}} \quad$ liquid density, $\mathrm{kg} / \mathrm{m}^{3}$

$52 \delta \quad$ depth of groove channel, $\mathrm{m}$

53

54 Subscripts

$55 \quad 0 \quad$ initial 


$\begin{array}{lll}56 & \text { chc } & \text { ceramic heating chips } \\ 57 & \text { fb } & \text { flow boiling } \\ 58 & \text { i } & \text { inside } \\ 59 & \text { in } & \text { inlet } \\ 60 & l & \text { liquid } \\ 61 & \text { o } & \text { outside } \\ 62 & \text { out } & \text { outlet } \\ 63 & \text { pre } & \text { pre-heater } \\ 64 & \text { sat } & \text { saturation } \\ 65 & \text { s } & \text { smooth } \\ 66 & \text { v } & \text { vapor } \\ 67 & \text { W } & \text { tube wall }\end{array}$

\section{Introduction}

With the rapid development and increased complexity in electronic systems of space vehicle, high heat flux cooling techniques have received much attention in recent years. Compared with single-phase thermal control system, two-phase flow boiling in tube is a significant and efficient method for high heat flux removal due to the utilization of latent heat of vaporization. Besides that, well designed flow boiling system is able to provide higher values of heat transfer coefficient at lower mass flux, and offer a more uniform surface temperature distribution due to the constant fluid temperature in saturation state $[1,2]$.

Numerous studies have focused on the heat transfer mechanism of flow boiling and the effect of operating parameters. Since R134a is an environmental friendly refrigerant with zero ODP (ozone-depleting-potential), flow boiling heat transfer of R134a has received much attention. Grauso et al. [3] experimentally measured the local heat transfer performances of R1234ze(E) and R134a in a

81 horizontal smooth tube and found that heat transfer coefficients of R134a are about $15 \%$ higher than those of R1234ze(E). Kundu et al. [4] also found that heat transfer coefficients of R134a are 55\%-87\% higher than those of R407C in a horizontal smooth tube. Xu et al. [5] conducted experiments on flow 
boiling of R134a in smooth horizontal tubes and found that heat transfer coefficient is higher for smaller tubes and higher saturation pressure. Lee et al. [6] systematically analyzed the flow patterns and the dominant heat transfer mechanisms of R134a flow boiling in micro-channels. They found that low vapor qualities are associated with slug flow and dominated by nucleate boiling while high vapor qualities are associated with annular flow and dominated by convective boiling.

In order to further improve the flow boiling heat transfer performance and optimize the cooling efficiency, many kinds of tubes with enhanced surfaces have been developed [7,8]. Numerous investigations on flow boiling in various tubes with enhanced surfaces such as reentrant grooves [9-11], micro-fins [12-14], and surface coatings [15-17] were reported, and the heat transfer enhancement characteristics were analyzed and discussed. Among these enhanced surfaces, " $\Omega$ "-shaped groove has been proved to provide higher thermal control performance due to the powerful heat transfer capability, stable operation under microgravity conditions and high degree of temperature uniformity [18-23]. Owing to the wonderful performance of " $\Omega$ "-shaped grooves, a few investigations on heat pipe with " $\Omega$ "-shaped grooves have been conducted. Thomas et al. [18] developed a finite element model to analyze the fully developed laminar flow in heat pipes with reentrant (similar to " $\Omega$ "-shaped) grooves. The parametric analysis showed a strong effect of reentrant groove geometry on flow characteristics. Chen et al. [19] numerically studied the maximum heat transfer capability of two-phase flow in heat pipes with axial " $\Omega$ "-shaped grooves, and analyzed the effects of vapor core, groove structure and groove size on heat transfer performance. The numerical results showed a strong effect of “ $\Omega$ ”-shaped groove geometry on both flow and thermal performance. The heat transfer capability increased with the decrease of groove inlet width and the increase of groove diameter, while the effective thermal conductivity increased with the decrease of groove inlet width. After that, Chen et al. [20] also developed a transient model and conducted experiments for the thermal response characteristics of heat pipes with axially " $\Omega$ "-shaped grooves. Zhang et al. [21] utilized genetic algorithm to optimize the heat transfer capability and total thermal resistance for heat pipes with " $\Omega$ "-shaped grooves. It was found that smaller groove inlet width and larger groove diameter make the heat transfer capability higher, however make the effective thermal conductivity lower; larger groove number and tube inner diameter will enhance the heat transfer capability. Bai et 

which consisted of a V-shaped channel connected to " $\Omega$ "-shaped groove. This hybrid axial groove showed a great enhancement on heat transfer performance compared with that of rectangular groove, due to a considerable increase in heat transfer area and reduction in liquid film thickness. Shibano et al. [23] conducted experiments to study the thermal behaviors of an $\Omega$ grooved heat pipe and a rectangular grooved heat pipe. They found that the $\Omega$ grooved heat pipe need less heat input than rectangular grooved heat pipe to start-up. heat transfer performance of heat pipe. As the evaporation process in of two-phase flow boiling is similar to that in heat pipe, " $\Omega$ "-shaped grooves may also enhance heat transfer of flow boiling. However, there is relatively little work on flow boiling heat transfer with " $\Omega$ "-shaped grooves in the literature until now. Moreover, the heat transfer characteristics, flow patterns and effect mechanism of “ $\Omega$ "-shaped grooves in heat pipe are quite different from two-phase flow boiling, since heat pipe is a passive cooling method with a small amount of working fluid circulated by capillary pressure gradient at the liquid-vapor interface and without a need for external pumping power [24]. Therefore, attention should be paid to whether the application of " $\Omega$ "-shaped grooves in flow boiling could enhance the heat transfer coefficient or not. What's more, heat pipe with axially " $\Omega$ "-shaped grooves has shown stable operation under microgravity conditions and non-sensitivity with gravity direction [25]. But as mass flux in flow boiling is much higher than that in heat pipe, the effect of gravity direction on flow boiling in " $\Omega$ "-shaped grooved tube is still unclear. Thus, it is of necessary to study the effect of gravity direction on flow boiling in " $\Omega$ ”-shaped grooved tube.

To solve above problems, an experiment system of flow boiling in axially " $\Omega$ "-shaped grooved tube with refrigerant R134a as the working fluid was set up in this paper. The heat transfer enhancement of " $\Omega$ "-shaped grooves on flow boiling and the effect of gravity direction were investigated. The effects of vapor quality, heat flux and mass flux on flow boiling heat transfer coefficient were also investigated and compared with smooth tube. To study the effect of gravity direction, flow boiling experiments in different flow direction such as horizontal, upward and downward vertical were also conducted. 


\section{Experimental setup and procedure}

\subsection{Test tube section}

A flow boiling test tube with axially " $\Omega$ "-shaped grooves is manufactured in this paper to enhance the flow boiling heat transfer performance. The cross-section geometry of the " $\Omega$ "-shaped grooves is shown in Fig.1 and the relevant geometry parameters are listed in Table 1. As shown in Fig.1, 20 " $\Omega$ "-shaped grooves with inner diameter of $1 \mathrm{~mm}$ are axially arranged inside the test tube. The inlet channel of the " $\Omega$ "-shaped groove is a rectangular channel with $0.3 \mathrm{~mm}$ width and $0.53 \mathrm{~mm}$ depth. The test tube is fabricated of a annular aluminum tube (inner diameter of $10 \mathrm{~mm}$, outside diameter of $15 \mathrm{~mm}$ ) with external fin of $30 \mathrm{~mm}$ length and $2 \mathrm{~mm}$ width. The schematic and photograph of test tube are shown in Fig. 2. The total length of test tube is $400 \mathrm{~mm}$. In order to achieve a more uniform heating effect, the test tube is heated by 16 ceramic heating chips uniformly arranged on the outside wall of test tube. The heating chips used in this study have a $90 \mathrm{~mm}$ length, $10 \mathrm{~mm}$ width and $160 \mathrm{~W}$ capacity per chip. Thermal silicone grease is coated between the heating chips and the test tube in order to reduce the contact thermal resistance and to further ensure the uniform heating effect. The inlet and outlet temperatures of working fluid are measured by T-type armored thermocouples which are invasively installed in the inlet and outlet of test tube. To measure the wall temperature in the middle of test tube, $4 \mathrm{~T}$-type thermocouples are arranged outside at the top, two sides of the middle and bottom of the tube, as shown in Fig.1(a). The outside wall temperature is taken as the average of 4 outside wall temperatures. The test tube is surrounded by insulation materials to reduce heat loss to the surroundings.

\subsection{Flow boiling experimental system}

A flow boiling experimental system with refrigerant R134a as the working fluid is conducted in this paper. Fig.3 illustrates the schematic of the experimental setup. The test system consists of fluid supply section, flow control section, pre-heating section, test section and liquid recycling section. In experiments, the saturated R134a liquid is stored in a high pressure tank. The tank is heated by silicone heater wires to keep the inside temperature and pressure stable. At first, the working fluid is 
precooled by a plate type condenser to ensured a sub-cooled refrigerant. The sub-cooled refrigerant after the condenser is included to avoid the occurrence of liquid-vapor two phase flow during the flow throttling process. The refrigerant flow rate is controlled by a flow control valve. A pre-heater is installed after the flowmeter to control the vapor quality at the inlet of test tube by regulating the power supply according to the inlet temperature and flow rate. Then the two phase flow enters the test tube and the flow boiling heat transfer characteristics are tested and measured. After the heating process, two phase flow with a higher vapor quality flows into a liquid-vapor separator. The vapor phase R134a is separated and released into the atmosphere. The saturated liquid is cooled by a plate type condenser to ensured a sub-cooled refrigerant and pumped into the test loop for recycle.

\subsection{Data calculation and uncertainty analysis}

\subsubsection{Data calculation}

In this study, the heat transfer coefficient, $h_{\mathrm{fb}}$, is the crucial parameter of interest in evaluating the flow boiling performance. It can be simply determined based on the convective heat transfer of the working fluid and the conductive heat transfer of the test tube wall as following:

$h_{\mathrm{fb}}=\left(\frac{T_{\mathrm{w}}-T_{\mathrm{sat}}}{q}-R_{\mathrm{w}}\right)^{-1}$

The outside wall temperature, $T_{\mathrm{w}}$, is the average of outside wall temperatures measured at the top, two sides of the middle and bottom of the test tube as following:

$$
T_{\mathrm{w}}=\frac{T_{1}+T_{2}+T_{3}+T_{4}}{4}
$$

The local saturation temperature, $T_{\text {sat }}$, is calculated by the liner interpolation of the inlet and outlet temperature of working fluid. This is because that the working fluid is always in the saturation state along the test tube. Thus, $T_{\text {sat }}$ is equal to the local fluid temperature. As the temperature drop along the test tube is very low, so $T_{\text {sat }}$ is simply calculated by the liner interpolation between the inlet and outlet temperatures.

$$
T_{\text {sat }}=\frac{L_{\text {in }}}{L} T_{\text {out }}+\frac{L_{\text {out }}}{L} T_{\text {in }}
$$

where, $L$ is the total length of the test tube. $L_{\text {in }}$ and $L_{\text {out }}$ are the distance from tube inlet and outlet to the measuring point, respectively, as illustrated in Fig.2(a). $T_{\text {in }}$ and $T_{\text {out }}$ are the inlet and outlet temperature 
of working fluid.

The heat flux, $q$, is generated by ceramic heating chips. It can be calculated by he following equation:

$q=\frac{P_{\mathrm{chc}}}{L \cdot C_{\mathrm{i}}}$

where, $P_{\text {chc }}$ is the total heating power of 16 ceramic heating chips. $L$ is the total length of test tube. $C_{\mathrm{i}}$ is the inner circumference of test tube cross section which can be determined by the following equation:

$$
C_{\mathrm{i}}=\pi \pi_{\mathrm{T}}+n d \mathcal{L}-n w+n \delta
$$

where, $D_{\mathrm{i}}$ is the inner diameter of test tube. $d$ is the diameter of groove. $n$ is the number grooves. $w$ is the width of groove inlet channel. $\delta$ is the length of groove inlet channel.

The thermal-conduction resistance of test tube with " $\Omega$ "-shaped groove, $R_{\mathrm{w}}$, is different from the case of smooth tube [26] which can be simply calculated by the thermal-conduction resistance equation:

$$
R_{\mathrm{w}, \mathrm{s}}=\frac{\ln \left(D_{\mathrm{o}} / D_{\mathrm{i}}\right)}{2 \pi k}
$$

where, $R_{\mathrm{w}, \mathrm{s}}$ is the thermal resistance of smooth tube. $D_{\mathrm{i}}$ and $D_{\mathrm{o}}$ are the inner diameter and outside diameter of smooth tube respectively. $k$ is the thermal conductivity of smooth tube. However, in this study, the inner wall of test tube is very complex, so Eq. 6 is not suitable here. To obtain $R_{\mathrm{w}}$ more accurately, a commercially available computer software (FLUENT) is adopted in this study to simulate the heat conduction of " $\Omega$ " tube. The simulation condition is set as follows: the inner wall of test tube is isothermal; top and bottom wall is heated by a constant heat flux; the other parts of test tube are isolated. Then the corresponding $R_{\mathrm{w}}$ is obtained based on simulation results.

The local vapor quality, $x$, can been estimated by an energy balance of the pre-heater and test tube by the following:

$$
x=\frac{\left(T_{0}-T_{\mathrm{sat}}\right) c_{\mathrm{p}, \mathrm{f}}}{h_{\mathrm{fg}}}+\frac{P_{\mathrm{pre}}+P_{\mathrm{chc}} L_{\mathrm{in}} / L}{Q \rho_{\mathrm{f}} h_{\mathrm{fg}}}
$$

where, $T_{0}$ is the initial temperature at the inlet of pre-heater. $T_{\text {sat }}$ is the local saturation temperature calculated by Equation (3). $h_{\mathrm{fg}}$ is the latent heat of vaporization of R134a. $P_{\text {pre }}$ is the heating power of 
pre-heater. $P_{\text {chc }}$ is the total heating power 16 ceramic heating chips. $L_{\text {in }}$ is the distance from tube inlet to the measuring point. $L$ is the total length of test tube. $Q$ is the volumetric flow rate of working fluid. $\rho_{\mathrm{f}}$ is the density of liquid R134a corresponding to $T_{0}$.

The mass flux, $G$, is calculated by the following equation:

$$
G=\frac{Q \cdot \rho_{\mathrm{f}}}{A_{\mathrm{i}}}
$$

The inner flow area of test tube, $A_{\mathrm{i}}$, can be determined by the following equation:

$$
A_{\mathrm{i}}=\pi D_{\mathrm{i}}^{2} / 4+n \pi d^{2} / 4+n \delta w
$$

where, $D_{\mathrm{i}}$ is the inner diameter of test tube. $d$ is the diameter of groove. $n$ is the number grooves. $w$ is the width of groove inlet channel. $\delta$ is the length of groove inlet channel.

\subsubsection{Uncertainty analysis}

The uncertainties of the various instruments and appliances used in this study are listed in Table 2. The temperatures are measured by T-type thermocouples and recorded by Agilent 34970A data acquisition system. The uncertainty of the calibrated T-type thermocouples is $\pm 0.1^{\circ} \mathrm{C}$. The temperature measurement uncertainty caused by the data acquisition system is $\pm 0.2^{\circ} \mathrm{C}$. The tube diameter is measured by Vernier calipers with uncertainty of $\pm 0.02 \mathrm{~mm}$ and the tube length is measured by meter ruler with uncertainty of $\pm 1 \mathrm{~mm}$. The uncertainty of volumetric flow rate is $\pm 2.5 \%$ caused by rotor flowmeter. The heating power uncertainty is $\pm 0.4 \%$ caused by TECMAN TM 9800 power meter.

Therefore, according to the error transfer formula:

$$
\sigma_{\mathrm{y}}=\sqrt{\sum_{i=1}^{n}\left(\frac{\partial f}{\partial x_{i}}\right)^{2} \sigma_{x_{i}}^{2}}
$$

the uncertainties in mass flux, heat flux, heat transfer coefficient and the vapor quality can be calculated as follows:

$$
\frac{\Delta G}{G}= \pm \sqrt{\left(\frac{\Delta Q}{Q}\right)^{2}+\left(\frac{\Delta A_{\mathrm{i}}}{A_{\mathrm{i}}}\right)^{2}}
$$




$$
\frac{\Delta x}{x}= \pm \sqrt{\left(\frac{\Delta T_{\text {sat }}}{T_{\text {sat }}}\right)^{2}+\left(\frac{\Delta P_{\text {pre }}}{P_{\text {pre }}}\right)^{2}+\left(\frac{\Delta P_{\text {chc }}}{P_{\text {chc }}}\right)^{2}+\left(\frac{\Delta L_{\text {in }}}{L_{\text {in }}}\right)^{2}+\left(\frac{\Delta L}{L}\right)^{2}+\left(\frac{\Delta Q}{Q}\right)^{2}}
$$

According to the experimental results, the ranges and maximum uncertainties of derived variables

are listed in Table. 3. The maximum uncertainties of mass flux, heat flux, heat transfer coefficient and the vapor quality are $\pm 3.8 \%, \pm 3.7 \%, \pm 14.4 \%$ and $\pm 5.4 \%$, respectively.

\section{Results and discussions}

Experiments are carried out with refrigerant R134a at saturation temperature of 20 , mass flux from 10 to $30 \mathrm{~kg} /\left(\mathrm{m}^{2} \mathrm{~s}\right)$, heat flux from 3 to $10 \mathrm{~kW} / \mathrm{m}^{2}$ and corresponding vapor quality from 0.07 to 0.82. The effects of vapor quality, heat flux and mass flux on flow boiling heat transfer coefficient are investigated and compared with that of smooth tube, in order to describe the heat transfer enhancement characteristics and effect mechanisms of " $\Omega$ "-shaped grooves. Flow boiling characteristics in different flow direction such as horizontal, upward and downward vertical are also investigated to study the effect of gravity direction.

\subsection{General correlation of smooth tube for comparison}

In order to evaluate the heat transfer enhancement effect of " $\Omega$ "-shaped grooves, a comparison between the experimental data and our previously proposed correlation for smooth tube [27] is performed. This correlation has been validated by a huge experimental database from 26 open literatures containing 2783 experimental points. It is developed based on the superposition of nucleate boiling and convective boiling contributions as following:

$$
h_{\mathrm{fb}}=\left[h_{\mathrm{cb}}^{2}+h_{\mathrm{nb}}^{2}\right]^{1 / 2}
$$


$h_{\mathrm{cb}}=0.0070 t_{+}^{1.00} \operatorname{Re}_{\mathrm{g}}^{0.14} \operatorname{Pr}_{\mathrm{f}}^{0.80} \frac{k_{\mathrm{f}}}{t}$

where, $t_{+}$is the dimensionless liquid film thickness. $R e_{\mathrm{g}}$ is the Reynolds number of vapor phase. $P r_{\mathrm{f}}$ is liquid Prandtl number. $k_{\mathrm{f}}$ is the thermal conductivity of liquid phase. $t$ is the liquid film thickness. Shekriladze [29]. The modified correlation is expressed as:

$h_{\mathrm{nb}}=0.69 \cdot 0.0122 \frac{k_{\mathrm{f}}}{r_{0}}\left(\frac{\left[p\left(\rho_{\mathrm{g}}^{-1}-\rho_{f}^{-1}\right)\right]^{0.5} \sigma c_{\mathrm{p}, \mathrm{f}} \rho_{\mathrm{f}}^{2} T_{\mathrm{sat}}}{\mu_{\mathrm{f}} h_{\mathrm{fg}}^{2} \rho_{\mathrm{g}}^{2}}\right)^{0.25}\left(\frac{r_{0}^{2} \rho_{\mathrm{g}} h_{f g} q}{\sigma k_{\mathrm{f}} T_{\mathrm{sat}}}\right)^{0.7}$

where, $r_{0}$ is the radius of nucleation site. $p$ is pressure. $r_{\mathrm{g}}$ and $r_{\mathrm{f}}$ are the density of vapor and liquid. $\sigma$ is surface tension. $m_{\mathrm{f}}$ is liquid viscosity.

As shown in Fig.4, this correlation provides very good predictions against the entire database, with $89.45 \%$ of the data falling within $\pm 30 \%$ error bands. Our previous research [27] showed that the prediction accuracy of this general correlation is much higher than the other top 5 prediction methods and got better consistency with the varying vapor quality. Due to its acceptable accuracy of prediction, this general correlation is adopted in this paper to predict the heat transfer coefficient of smooth tube. For comparison, the calculation condition of smooth tube is setting as the same condition of “ $\Omega$ ”-shaped grooved tube presented in this study.

\subsection{Flow boiling in horizontal tube}

Fig. 5-8 show the effects of mass flux, heat flux and vapor quality on heat transfer coefficient in horizontal tube. Fig. 5,6 illustrate the heat transfer coefficient as a function of vapor quality with mass flux as the varying parameter at heat flux of $3 \mathrm{~kW} / \mathrm{m}^{2}$ and $5 \mathrm{~kW} / \mathrm{m}^{2}$, respectively. The calculation results of smooth tube with the same inner diameter are presented to study the enhancement effect of “ $\Omega$ ”-shaped grooves. As shown in Fig. 5, heat transfer coefficient increases a lot with increasing mass flux at relatively low vapor quality below 0.4 and increases slightly when vapor quality is larger than 0.4. At low mass flux, heat transfer coefficient decreases slightly with the increase of vapor quality. However, at high mass flux of $30 \mathrm{~kg} /\left(\mathrm{m}^{2} \cdot \mathrm{s}\right)$, heat transfer coefficient increases a lot at first, reaches highest heat transfer coefficient at vapor quality of 0.3 , and then decreases with the increasing vapor quality. Compared with calculation results of smooth tube, the variation trend of heat transfer 
coefficient is the same as that of smooth tube except at high mass flux of $30 \mathrm{~kg} /\left(\mathrm{m}^{2}{ }^{2} \mathrm{~s}\right)$. What's more, it is crucial to note that the application of " $\Omega$ "-shaped grooves is able to enhance heat transfer coefficient of between 1.5 and 3.3 times at the same vapor quality compared to the smooth tube. Although the calculation deviation may be more than $30 \%$, the 1.5 and 3.3 times enhancement is also significant. Fig. 6 shows the effect of mass flux on heat transfer coefficient at heat flux of $5 \mathrm{~kW} / \mathrm{m}^{2}$. Similar to Fig. 5, the figure clearly shows a significant enhancement of heat transfer coefficient at the case of “ $\Omega$ "-shaped grooves. It is concluded that the application of " $\Omega$ "-shaped grooves could dissipate higher heat flux at the same condition compared with smooth tube.

Fig. 7,8 illustrate the heat transfer coefficient as a function of vapor quality with heat flux as the varying parameter at mass flux of $20 \mathrm{~kg} /\left(\mathrm{m}^{2} \cdot \mathrm{s}\right)$ and $30 \mathrm{~kg} /\left(\mathrm{m}^{2} \cdot \mathrm{s}\right)$, respectively. The calculation results of smooth tube with the same inner diameter are also presented for comparison. It is clear that the heat transfer coefficient increases a lot with the increase of heat flux at all the tested mass fluxes which coincide with the case of smooth tube. Besides that, it is notable that the effect of heat flux on heat transfer coefficient is significant while the effect of mass flux is not very sensitive (shown in Fig. 5,6). This indicates that heat transfer is dominated by nucleate boiling at the case of horizontal flow. As shown in Fig. 7, heat transfer coefficient decreases slightly with the increase of vapor quality. However, in Fig. 8, at high mass flux of $30 \mathrm{~kg} /\left(\mathrm{m}^{2} \cdot \mathrm{s}\right)$ and low heat flux of 3 and $5 \mathrm{~kW} / \mathrm{m}^{2}$, heat transfer coefficient increases to a peak value at first and then decreases with the increasing vapor quality which is different from the case of smooth tube. This peak value indicates that the heat transfer enhancement of " $\Omega$ "-shaped grooves is not only because of the increase in inner surface area.

\subsection{Upward flow boiling in vertical tube}

Upward flow boiling characteristics in vertical tube with " $\Omega$ "-shaped grooves and the effects of mass flux, heat flux and vapor quality on heat transfer coefficient are shown in Fig. 9-11. The calculation results of upward flow inside vertical smooth tube with the same inner diameter are also presented for comparison. Fig. 9 shows the heat transfer coefficient as a function of vapor quality with mass flux as the varying parameter at heat flux of $5 \mathrm{~kW} / \mathrm{m}^{2}$. It is shown that the heat transfer coefficient increases slightly at relatively low vapor quality below 0.2 and is fairly constant when 
vapor quality is larger than 0.2 . Additionally, the heat transfer coefficient shows only mild sensitivity to mass flux in upward flow which coincides with the case of smooth tube. What's more, similar to horizontal flow, the application of " $\Omega$ "-shaped grooves is able to enhance heat transfer coefficients of between 1.5 and 1.8 times compared to the upward vertical smooth tube. It is concluded that the application of " $\Omega$ "-shaped grooves could also enhance the heat transfer performance of upward flow inside vertical tube.

Fig. 10,11 illustrate the heat transfer coefficient as a function of vapor quality with heat flux as the varying parameter at mass flux of $20 \mathrm{~kg} /\left(\mathrm{m}^{2} \cdot \mathrm{s}\right)$ and $30 \mathrm{~kg} /\left(\mathrm{m}^{2} \cdot \mathrm{s}\right)$, respectively. The heat transfer coefficient increases a lot with the increase of heat flux at both mass flux of $20 \mathrm{~kg} /\left(\mathrm{m}^{2 .} \mathrm{s}\right)$ and $30 \mathrm{~kg} /\left(\mathrm{m}^{2} \cdot \mathrm{s}\right)$. It is clear that heat flux has a strong impact on heat transfer coefficient while the effect of mass flux and vapor quality is not very sensitive, which coincides with the case of smooth tube. This indicates that the heat transfer is also dominated by nucleate boiling in the case of upward flow inside “ $\Omega$ ”-shaped grooved tube. Similarly, thanks to the application of " $\Omega$ "-shaped grooves, the heat transfer coefficient of upward flow is enhanced between 1.5 and 2.2 times compared to the smooth tube.

\subsection{Downward flow boiling in vertical tube}

Downward flow boiling characteristics in vertical tube with " $\Omega$ "-shaped grooves and the effects of mass flux, heat flux and vapor quality on heat transfer coefficient are shown in Fig. 12-14. To study the effect of gravity direction, the experimental results of upward flow inside vertical tube with “ $\Omega$ ”-shaped grooves are presented for comparison. Fig. 12 shows the heat transfer coefficient as a function of vapor quality with mass flux as the varying parameter at heat flux of $5 \mathrm{~kW} / \mathrm{m}^{2}$. At the same mass flux, heat transfer coefficient decreases slowly with the increasing vapor quality in the case of downward flow which is different from that of upward flow. Besides that, the mass flux has a stronger influence on heat transfer coefficient in the case of downward flow than the case of upward flow. This indicates that the heat transfer mechanism of " $\Omega$ "-shaped grooved tube is quite different from that of smooth tube. Nucleate boiling is not the only dominant heat transfer mechanism in the case of downward flow.

Fig. 13,14 show the heat transfer coefficient as a function of vapor quality with heat flux as the 
varying parameter at mass flux of $20 \mathrm{~kg} /\left(\mathrm{m}^{2} \cdot \mathrm{s}\right)$ and $30 \mathrm{~kg} /\left(\mathrm{m}^{2} \cdot \mathrm{s}\right)$, respectively. It is clear that the variation trend of heat transfer coefficient is quite different between downward flow and upward flow. With the increase of vapor quality, heat transfer coefficient decreases in the case of downward flow, however in upward flow, heat transfer coefficient is almost constant. With the increase of heat flux, heat transfer coefficient decreases apparently in the case of downward flow, however in upward flow, heat transfer coefficient increases on the contrary. Additionally, heat transfer coefficient of downward flow is much larger than that of upward flow, especially at low heat flux. At low heat flux of $3 \mathrm{~kW} / \mathrm{m}^{2}$, heat transfer coefficient of downward flow is as high as 5.1 times that of upward flow, while the highest ratio is only 1.8 at high heat flux of $10 \mathrm{~kW} / \mathrm{m}^{2}$. These results are contrary to the smooth tube cases reported in reference [30], in which heat transfer coefficient of upward flow is much larger than that of downward flow. This indicates that the effect of gravity on heat transfer performance in " $\Omega$ "-shaped grooved tube is quite different from that of smooth tube.

In order to clearly understand the effect mechanism of gravity direction on surface temperature, some typical flow pictures of the three flow directions are shown in Fig. 15. The pictures show the flow pattern in a smooth transparent tube connected to the test tube at mass flux of $30 \mathrm{~kg} /\left(\mathrm{m}^{2} \cdot \mathrm{s}\right)$ and vapor quality of 0.3 . It should be noted that the flow pattern in smooth tube can not fully reflect the flow boiling characteristics in test tube due to the application of " $\Omega$ "-shaped grooves and the nucleate boiling in heating process. However, it is very hard to achieve visualization under current experiment condition. Thus, these pictures could offer reference of the possible flow patterns. Generally, flow patterns were classified into intermittent flow, annular flow, stratified flow, stratified-wavy flow and mist flow [27]. In this paper, both annular flow and stratified-wavy flow are encountered. In the experiments of vertical upward and downward flow, the flow patterns are always annular flow. However, in horizontal flow, stratified-wavy flow shows up due to the act of the gravity. Fig. 15(a) shows the stratified-wavy flow in horizontal tube. When the flow is horizontal, gravity acts normally on the flow, thus the liquid flows at the bottom of the tube and the vapor flows at the top. In the case of stratified flow, flow boiling heat transfer coefficient is strongly related to the liquid-tube wall contact area because nucleate boiling is dominant in this case. Fig. 15(b) shows the annual flow in upward vertical tube. When the flow is upward vertical, gravity acts opposite to the flow direction, 
reducing flow velocity and increasing liquid film thickness. However, the effect of shear stress on the liquid-vapor interface overcome the gravity of flow, thus the liquid phase flows on the tube wall as thick film with considerable waves on the liquid-vapor interface. Fig. 15(c) shows the annual flow in downward vertical tube. When the flow is downward vertical, gravity acts in the same direction as the flow, thus the liquid phase flows on the tube wall in the form of thin liquid film with large flow velocity.

According to flow patterns observed in smooth tube, the liquid-vapor distributions of " $\Omega$ "-shaped grooved test tube in different flow directions are schematized in Fig. 16. In the case of stratified-wavy flow in horizontal tube shown in Fig. 16(a), flow boiling heat transfer coefficient is strongly related to the liquid-tube wall contact area because nucleate boiling is dominant in this case. Thus the heat transfer performance becomes worse at higher vapor quality. Regarding to annual flow in vertical upward flow tube shown in Fig. 16(b), the liquid film thickness on the tube wall decreases with the increasing vapor quality. However, due to the lower flow velocity and thicker liquid film, the film is relatively thick even at higher vapor quality. This explains the non-sensitivity of vapor quality on heat transfer coefficient. As for annual flow in vertical downward flow tube shown in Fig. 16(c), even at very thin film thickness, its heat transfer coefficient is larger than that of upward flow. This indicates that nucleate boiling is not the only dominant heat transfer mechanism in the case of downward flow. Considering the high flow velocity, the possible explanation of high heat transfer coefficient may be enhanced convective boiling heat transfer. This means that the application of " $\Omega$ "-shaped grooves could enhance the convective boiling heat transfer which is different from the smooth tube.

\section{Conclusions}

To study the heat transfer enhancement mechanism of " $\Omega$ "-shaped grooves on flow boiling heat transfer, a flow boiling experimental system with refrigerant R134a as the working fluid was presented in this paper. The effects of vapor quality, heat flux and mass flux on flow boiling heat transfer coefficient were investigated and compared with smooth tube. Flow boiling characteristics in different flow direction such as horizontal, upward and downward vertical were also investigated to study the effect of gravity direction. And the key findings can be summarized as follows: 
408 (1) Flow boiling heat transfer performance is obviously enhanced by the application of " $\Omega$ "-shaped 409 grooves. The heat transfer coefficient in " $\Omega$ "-shaped grooved tube is 1.5 to 3.3 times higher than 410 smooth tubes in horizontal and vertical upward flow at present study. In addition, the enhancement 411 ratio vary with vapor quality, heat flux, mass flux and the flow direction.

412 (2) The variation trend of heat transfer coefficient on vapor quality is quite different between 413 horizontal, downward and upward flow. With the increase of vapor quality, heat transfer coefficient 414 shows a decreasing trend in horizontal and downward flow generally, however in upward flow, heat 415 transfer coefficient is almost constant.

416 (3) The effects of heat flux and mass flux on heat transfer coefficient vary with flow direction. In 417 horizontal and upward flow, heat flux shows a significant and positive impact while the effect of mass 418 flux is not very sensitive, which indicates that heat transfer is dominated by nucleate boiling. In 419 downward flow, mass flux shows a stronger positive impact while heat flux have negative impact, which means the dominant heat transfer mechanism have changed to convective boiling . (4) At present study, the highest heat transfer coefficient is achieved in downward flow, the second is in upward flow, and the lowest heat transfer coefficient occurs in horizontal flow. These results are contrary to the smooth tube, in which heat transfer coefficient of upward flow is much larger than that of downward flow. This indicates that the effect of gravity on heat transfer performance in " $\Omega$ ”-shaped grooved tube is quite different from that of smooth tube and the heat transfer enhancement caused by " $\Omega$ "-shaped grooves is not only because of the increase in inner surface area.

\section{Acknowledgement}

\section{References}

[1] Bertsch S S, Groll E A, Garimella S V. Review and comparative analysis of studies on saturated flow boiling in small channels. Nanoscale and Microscale Thermophysical Engineering, 2008, 12(3): 
[2] Kandlikar S G. History, advances, and challenges in liquid flow and flow boiling heat transfer in microchannels: a critical review. Journal of Heat Transfer, 2012, 134(3): 034001.

[3] Grauso S, Mastrullo R, Mauro A W, et al. Flow pattern map, heat transfer and pressure drops during evaporation of R-1234ze (E) and R134a in a horizontal, circular smooth tube: Experiments and assessment of predictive methods. International journal of refrigeration, 2013, 36(2): 478-491. [4] Kundu A, Kumar R, Gupta A. Heat transfer characteristics and flow pattern during two-phase flow boiling of R134a and R407C in a horizontal smooth tube. Experimental Thermal and Fluid Science, 2014, 57: 344-352.

[5] Xu Y, Fang X, Li G, et al. An experimental study of flow boiling heat transfer of R134a and $1143-1157$.

[6] Lee S H, Mudawar I. Investigation of flow boiling in large micro-channel heat exchangers in a refrigeration loop for space applications. International Journal of Heat and Mass Transfer, 2016, 97: 110-129.

[7] $\mathrm{Wu} \mathrm{Z}$, Sundén B. On further enhancement of single-phase and flow boiling heat transfer in micro/minichannels. Renewable and Sustainable Energy Reviews, 2014, 40: 11-27.

[8] Shojaeian M, Koşar A. Pool boiling and flow boiling on micro-and nanostructured surfaces. Experimental Thermal and Fluid Science, 2015, 63: 45-73.

[9] Suman B. A steady state model and maximum heat transport capacity of an electrohydrodynamically augmented micro-grooved heat pipe. International journal of heat and mass transfer, 2006, 49(21): 3957-3967.

[10] Dong T, Yang Z, Bi Q, et al. Freon R141b flow boiling in silicon microchannels heat sinks: experimental investigation. Heat and Mass Transfer, 2008, 44(3): 315-324.

[11] Zhang X, Zhang J, Ji H, et al. Heat transfer enhancement and pressure drop performance for R417A flow boiling in internally grooved tubes. Energy, 2015, 86: 446-454.

[12] Ma A, Wei J, Yuan M, et al. Enhanced flow boiling heat transfer of FC-72 on micro-pin-finned surfaces. International Journal of Heat and Mass Transfer, 2009, 52(13): 2925-2931. 
[13] Padovan A, Del Col D, Rossetto L. Experimental study on flow boiling of R134a and R410A in a horizontal microfin tube at high saturation temperatures. Applied Thermal Engineering, 2011, 31(17): 3814-3826.

[14] Diani A, Mancin S, Rossetto L. R1234ze (E) flow boiling inside a $3.4 \mathrm{~mm}$ ID microfin tube. International Journal of Refrigeration, 2014, 47: 105-119.

[15] Khanikar V, Mudawar I, Fisher T. Effects of carbon nanotube coating on flow boiling in a micro-channel. International Journal of Heat and Mass Transfer, 2009, 52(15): 3805-3817.

[16] Kousalya A S, Hunter C N, Putnam S A, et al. Photonically enhanced flow boiling in a channel coated with carbon nanotubes. Applied Physics Letters, 2012, 100(7): 071601.

[17] Yang F, Li W, Dai X, et al. Flow boiling heat transfer of HFE-7000 in nanowire-coated microchannels. Applied Thermal Engineering, 2016, 93: 260-268.

[18] Thomas S K, Damle V C. Fluid flow in axial reentrant grooves with application to heat pipes. Journal of thermophysics and heat transfer, 2005, 19(3): 395-405.

[19] Chen Y, Zhang C, Shi M, et al. Study on flow and heat transfer characteristics of heat pipe with axial " $\Omega$ "-shaped microgrooves. International Journal of Heat and Mass Transfer, 2009, 52(3): 636-643.

[20] Chen Y, Yao F, Shi M. Thermal response of a heat pipe with axially " $\Omega$ ”-shaped microgrooves. International Journal of Heat and Mass Transfer, 2012, 55(15): 4476-4484.

[21] Zhang C, Chen Y, Shi M, et al. Optimization of heat pipe with axial “ $\Omega$ ”-shaped micro grooves based on a niched Pareto genetic algorithm (NPGA). Applied Thermal Engineering, 2009, 29(16): $3340-3345$.

[22] Bai L, Lin G, Peterson G P. Evaporative heat transfer analysis of a heat pipe with hybrid axial groove. Journal of Heat Transfer, 2013, 135(3): 031503.

[23] Shibano Y, Ogawa H. Thermal Behavior of Axial Groove Heat Pipe under Gravity: Dependence of Groove Shape and Orientation. 45th International Conference on Environmental Systems, 2015.

[24] Faghri A. Review and advances in heat pipe science and technology. Journal of Heat Transfer, 2012, 134(12): 123001.

[25] Dubois M, Mullender B, Van Oost S, et al. Space qualification of high capacity grooved heat 
pipes. SAE Technical Paper, 1995.

[26] Kundu A, Kumar R, Gupta A. Comparative experimental study on flow boiling heat transfer characteristics of pure and mixed refrigerants. International journal of refrigeration, 2014, 45: $136-147$.

[27] Yuan S, Cheng W L, Nian Y L, et al. Evaluation of prediction methods for heat transfer coefficient of annular flow and a novel correlation. Applied Thermal Engineering, 2016.

[28] Cioncolini A, Thome J R. Algebraic turbulence modeling in adiabatic and evaporating annular two-phase flow. International Journal of Heat and Fluid Flow, 2011, 32(4): 805-817.

[29] Shekriladze I G. Boiling heat transfer: mechanisms, models, correlations and the lines of further research. The Open Mechanical Engineering Journal, 2008, 2(1): 104-127.

[30] Mohseni S G, Akhavan Behabadi M A. Flow pattern visualization and heat transfer characteristics of R-134a during evaporation inside a smooth tube with different tube inclinations. International Communications in Heat and Mass Transfer, 2014, 59: 39-45. s. 


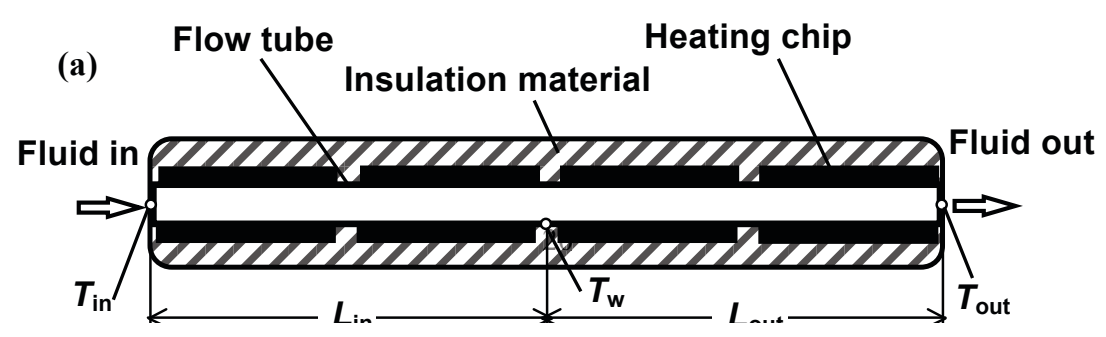




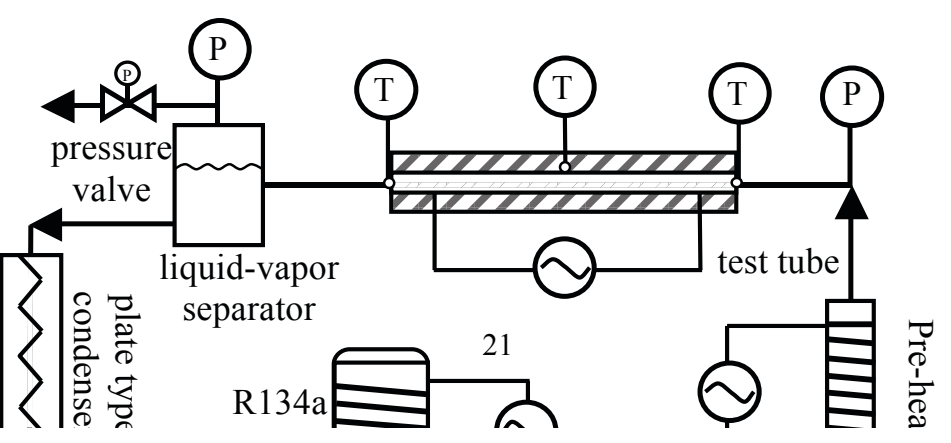


581

582

583

584

585

586

587

588

589

590

591

592

593

594

595

596

597

598

599 


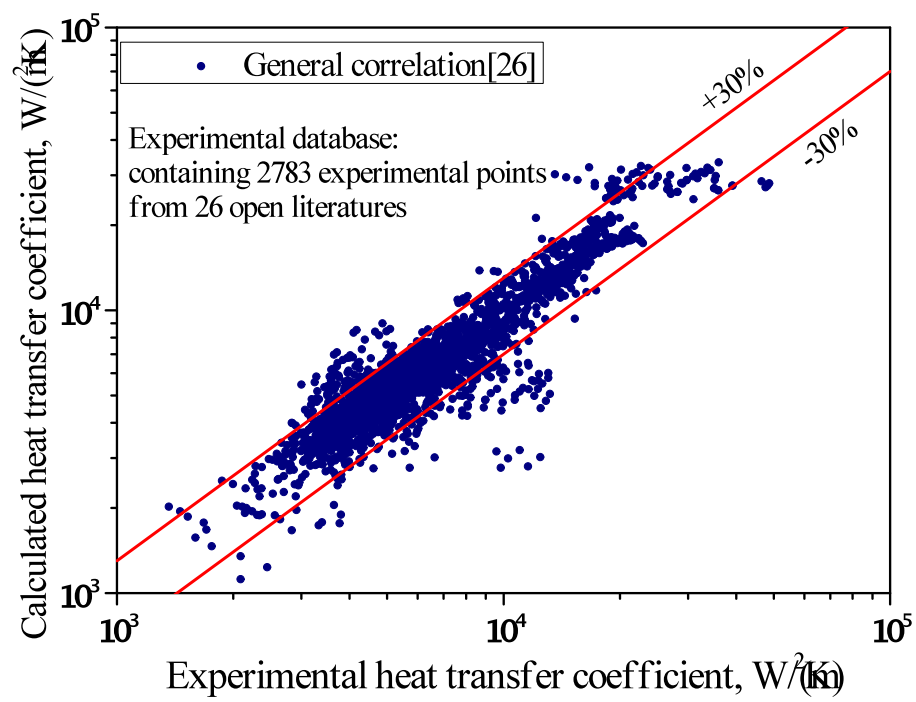

600

Fig.4 Predictions accuracy of the general flow boiling heat transfer correlations

602

603

604

605

606

607

608

609

610

611

612

613

614

615

616

617

618 


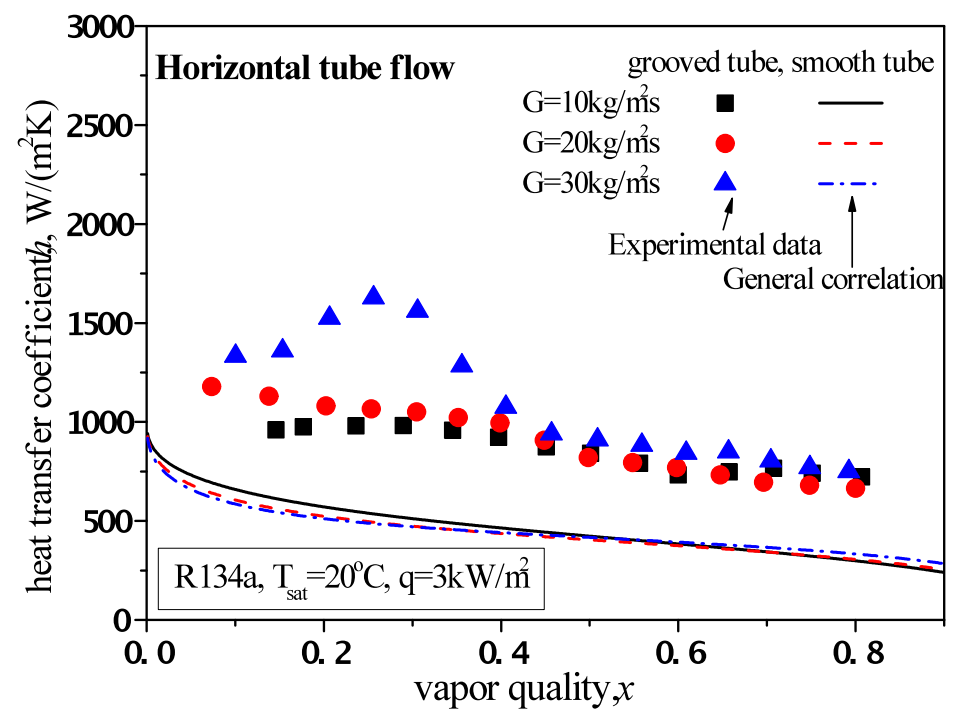

619

Fig.5 Heat transfer coefficient of horizontal flow boiling at heat flux of $q=3 \mathrm{~kW} / \mathrm{m}^{2}$.

621

622

623

624

625

626

627

628

629

630

631

632

633

634

635

636

637 


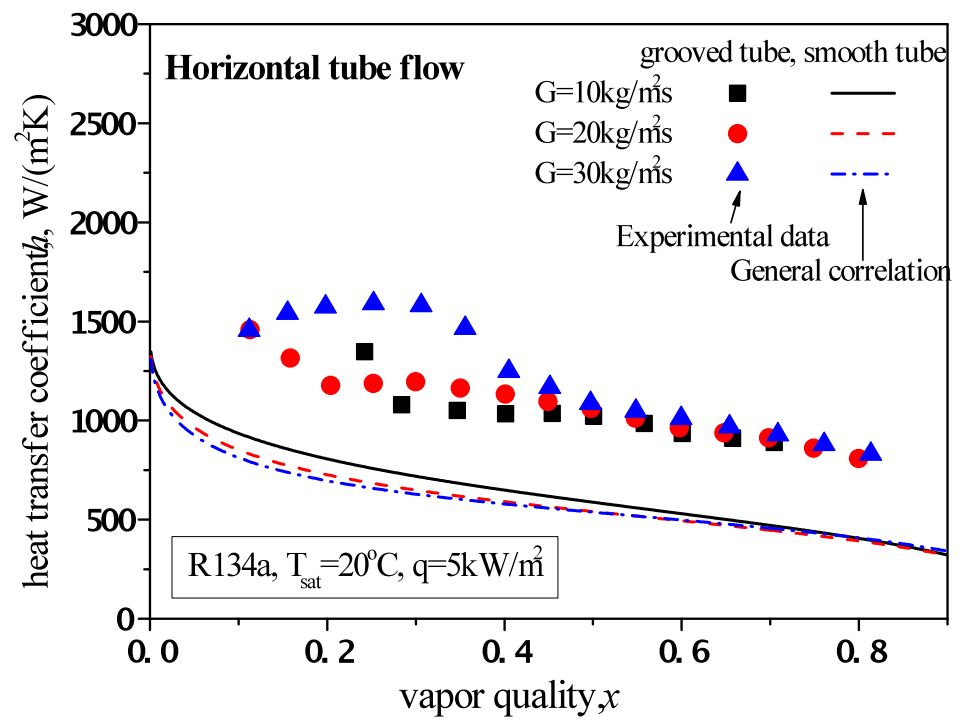

638

Fig.6 Heat transfer coefficient of horizontal flow boiling at heat flux of $q=5 \mathrm{~kW} / \mathrm{m}^{2}$.

640

641

642

643

644

645

646

647

648

649

650

651

652

653

654

655

656 


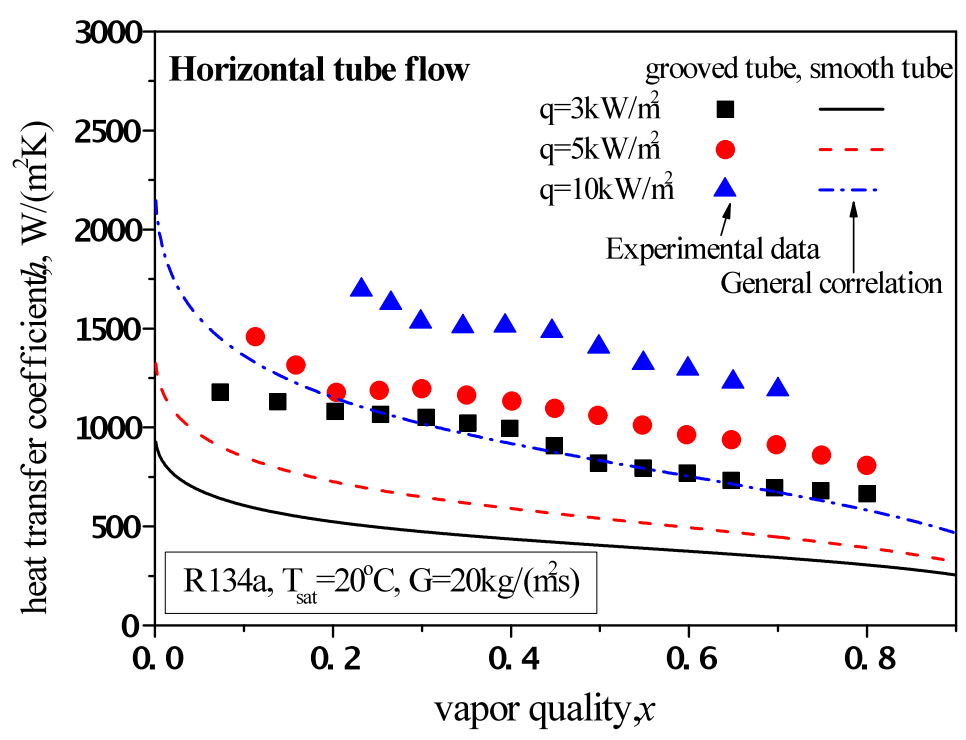

657

658

Fig.7 Heat transfer coefficient of horizontal flow boiling at mass flux of $G=20 \mathrm{~kg} /\left(\mathrm{m}^{2} \cdot \mathrm{s}\right)$.

659

660

661

662

663

664

665

666

667

668

669

670

671

672

673

674 


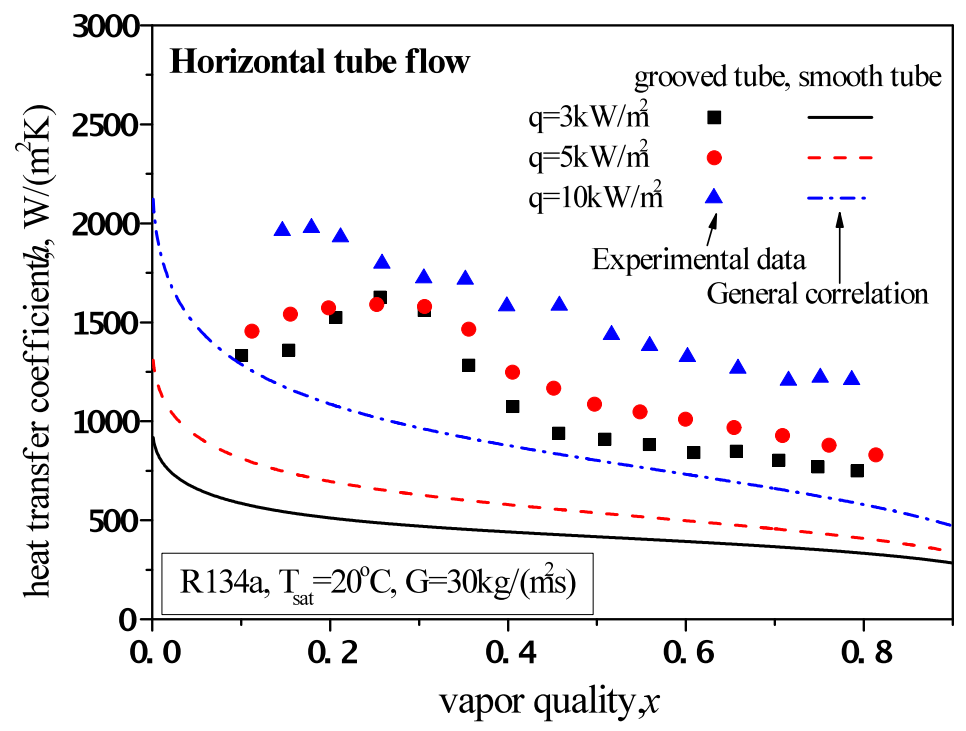

675

Fig. 8 Heat transfer coefficient of horizontal flow boiling at mass flux of $G=30 \mathrm{~kg} /\left(\mathrm{m}^{2} \cdot \mathrm{s}\right)$.

677

678

679

680

681

682

683

684

685

686

687

688

689

690

691

692 


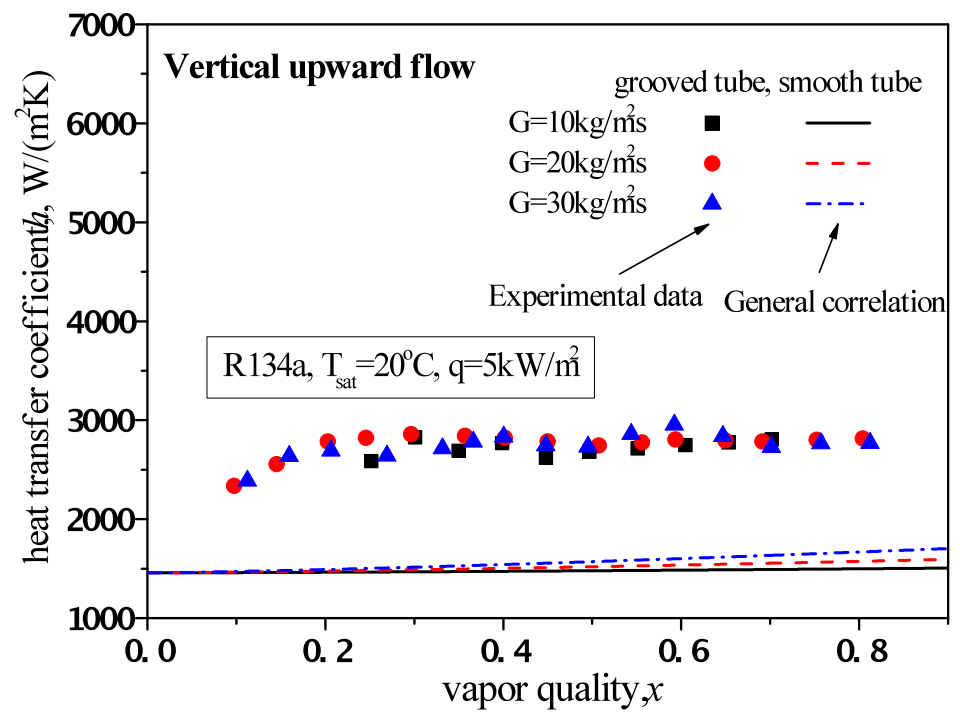

693

Fig.9 Heat transfer coefficient of upward flow boiling at heat flux of $q=5 \mathrm{~kW} / \mathrm{m}^{2}$.

695

696

697

698

699

700

701

702

703

704

705

706

707

708

709

710

711 


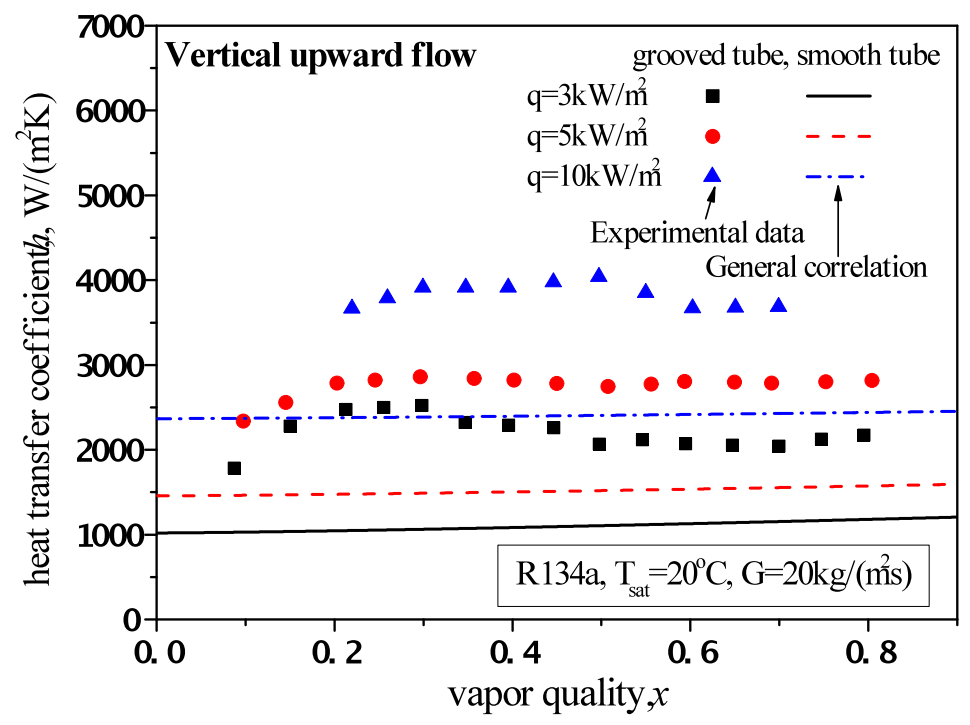

712

Fig.10 Heat transfer coefficient of upward flow boiling at mass flux of $G=20 \mathrm{~kg} /\left(\mathrm{m}^{2} \cdot \mathrm{s}\right)$. 


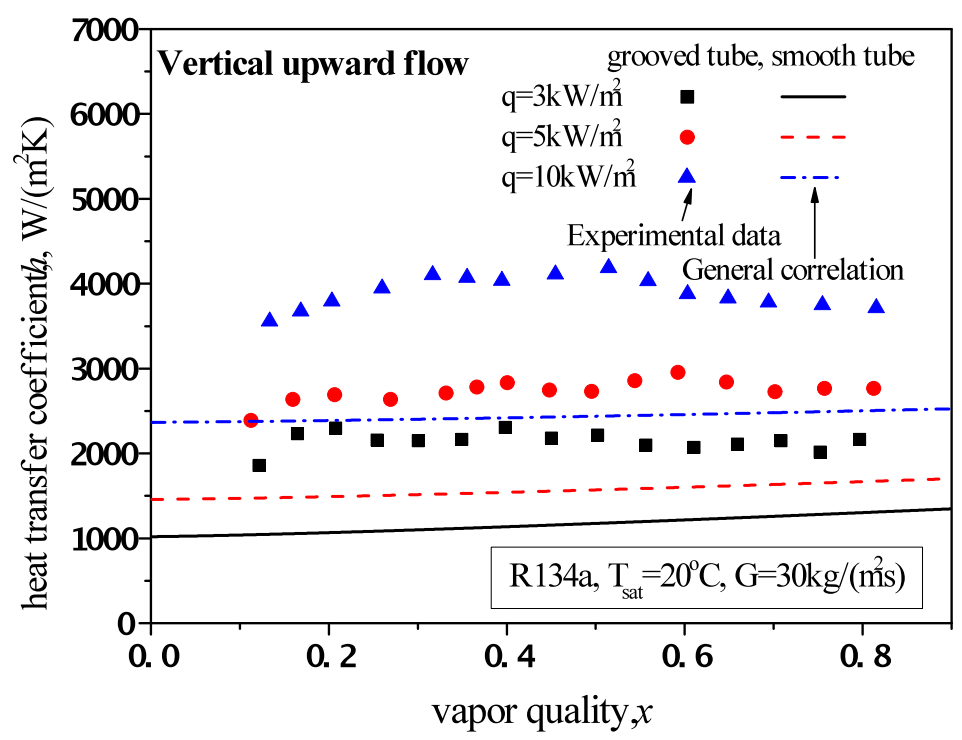

730

Fig.11 Heat transfer coefficient of upward flow boiling at mass flux of $G=30 \mathrm{~kg} /\left(\mathrm{m}^{2} \cdot \mathrm{s}\right)$. 


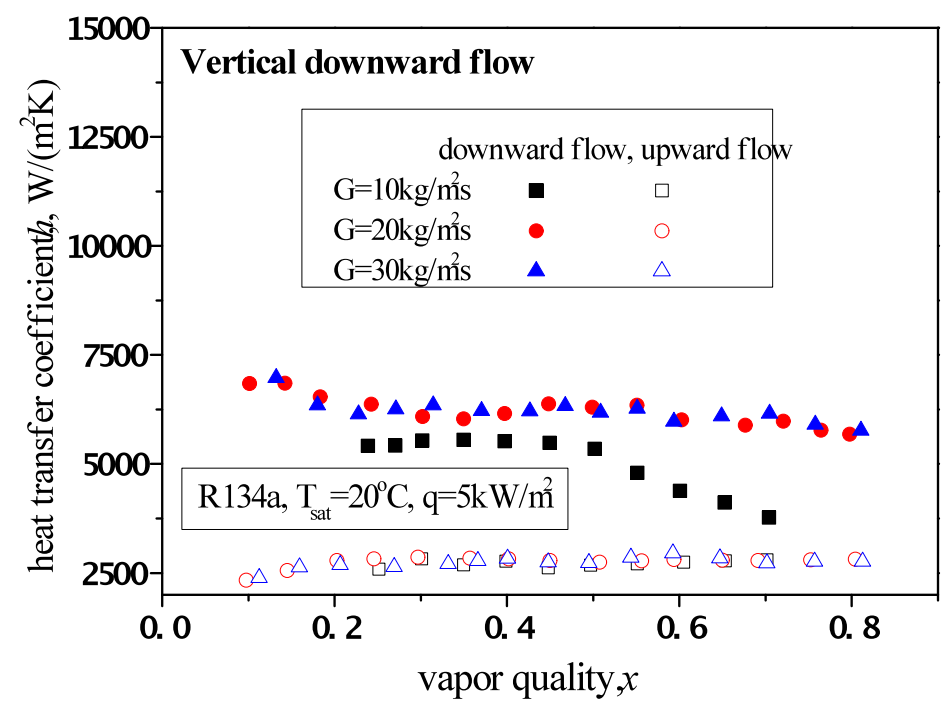

748

Fig.12 Heat transfer coefficient of downward flow boiling at heat flux of $q=5 \mathrm{~kW} / \mathrm{m}^{2}$.

750

751

752

753

754

755

756

757

758

759

760

761

762

763

764

765

766 


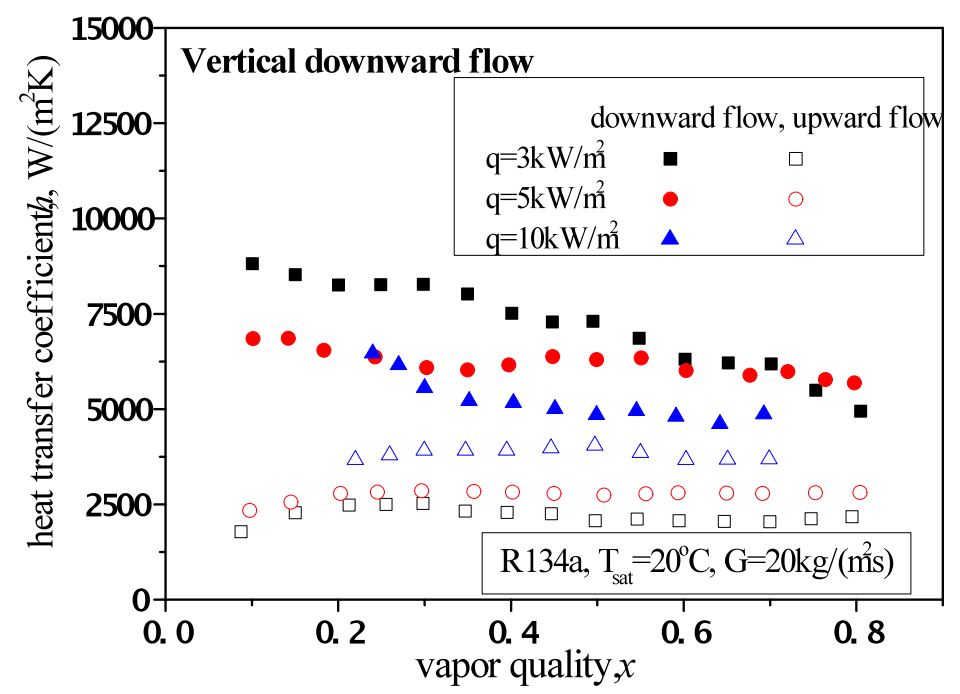

767

Fig.13 Heat transfer coefficient of downward flow boiling at mass flux of $G=20 \mathrm{~kg} /\left(\mathrm{m}^{2} \cdot \mathrm{s}\right)$.

769

770

771

772

773

774

775

776

777

778

779

780

781

782

783

784 


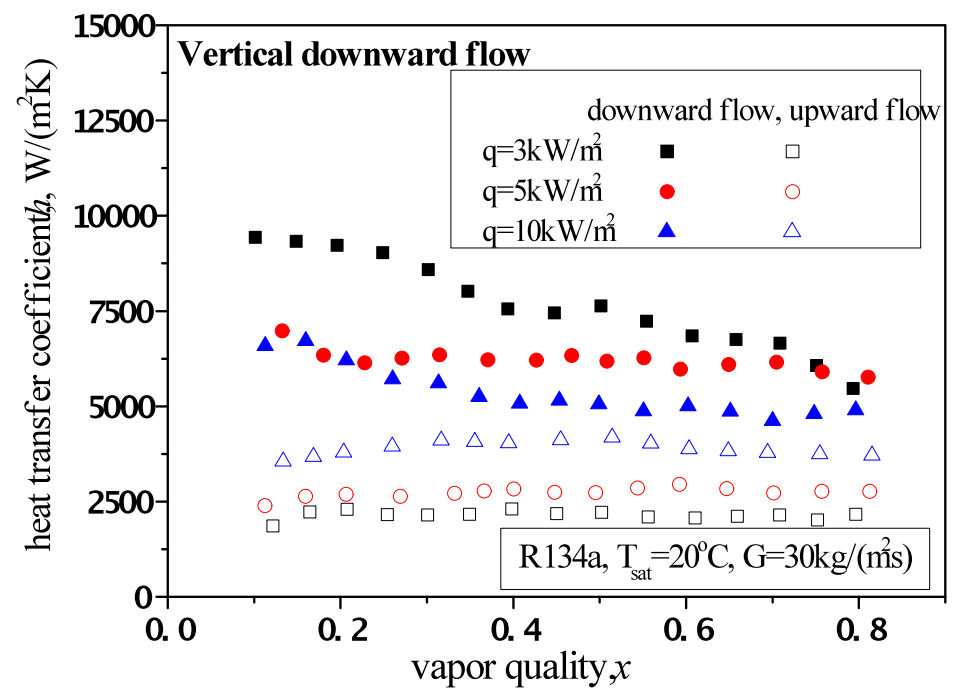

785

Fig.14 Heat transfer coefficient of downward flow boiling at mass flux of $G=30 \mathrm{~kg} /\left(\mathrm{m}^{2} \cdot \mathrm{s}\right)$. 
Flow pattern in $6.5 \mathrm{~mm}$ smooth transparent tube

(a) horizontal tube

(b) vertical upward

(c) vertical downward

(a)

$G=30 \mathrm{~kg} /\left(\mathrm{m}^{2 \cdot} \mathrm{s}\right), x=0.3$

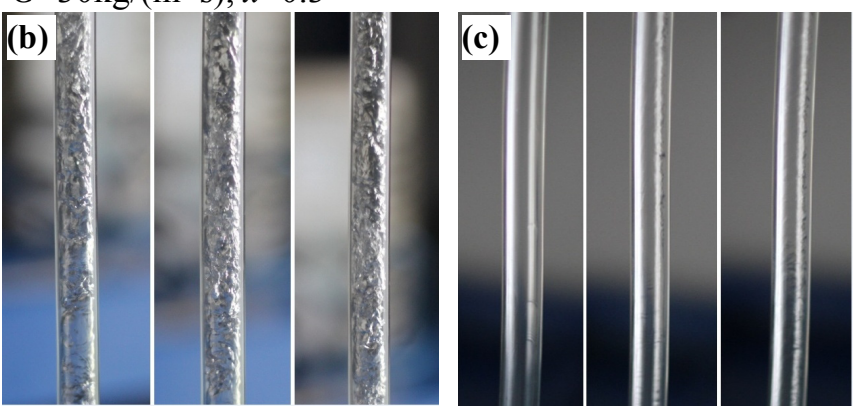

Fig.15 Photograph of flow patterns in smooth transparent tube connected to test tube .

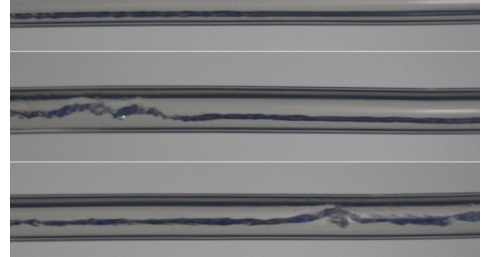

805

806

807

808

809

810

811

812

813

814

815

816

817

818

819

820

821 

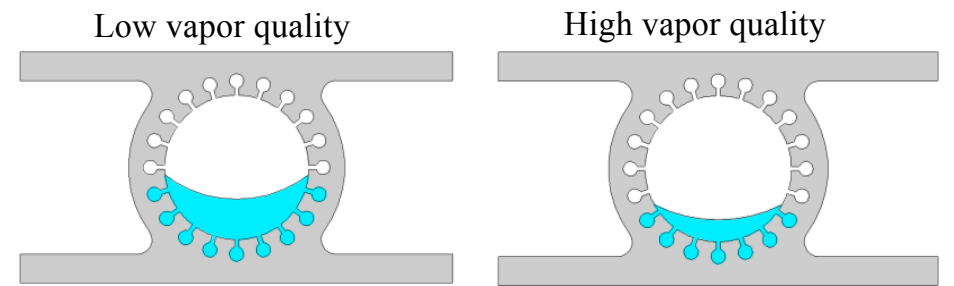

(a) Horizontal tube

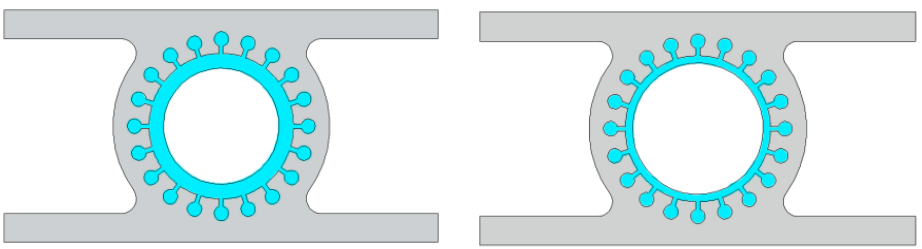

(b) Vertical upward flow tube
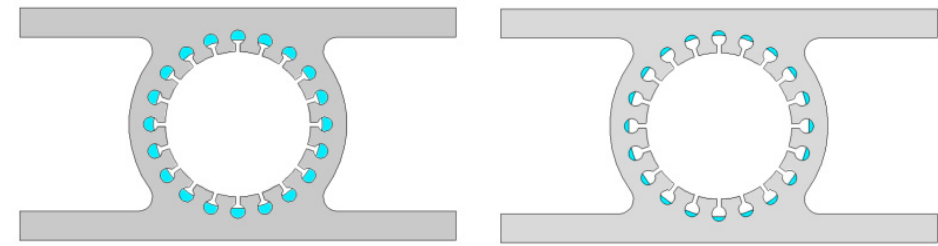

(c) Vertical downward flow tube 


\begin{tabular}{lc}
\hline Parameters & Value \\
\hline Number of grooves, $n$ & 20 \\
\hline Groove diameter, $d / \mathrm{mm}$ & 1.0 \\
\hline Groove inlet width, $w / \mathrm{mm}$ & 0.3 \\
\hline Groove inlet depth, $\delta / \mathrm{mm}$ & 0.5 \\
\hline Test tube inside diameter, $D_{\mathrm{i}} / \mathrm{mm}$ & 10 \\
\hline Test tube outside diameter, $D_{\mathrm{o}} / \mathrm{mm}$ & 15 \\
\hline Test tube length, $L / \mathrm{m}$ & 0.4 \\
\hline
\end{tabular}

840 
Table 2. Instruments and appliances

\begin{tabular}{lll}
\hline Parameter & Apparatus & Accuracy \\
\hline Temperature & $\begin{array}{l}\text { T-type thermocouple } \\
\text { Agilent 34970A data acquisition system }\end{array}$ & $\pm 0.1^{\circ} \mathrm{C}$ \\
\hline Tube diameter & Vernier calipers & $\pm 0.02 \mathrm{~mm}$ \\
\hline Tube length & Meter ruler & $\pm 1 \mathrm{~mm}$ \\
\hline Volume flow rate & Rotor flowmeter & $\pm 2.5 \%$ \\
\hline Heating power & TM 9800 power meter & $\pm 0.4 \%$ \\
\hline
\end{tabular}

859

860

861

862

863

864

865

866

867

868

869

870

871

872

873

874

875

876

877

878 


\begin{tabular}{llc}
\hline Parameter & Range & Uncertainty \\
\hline Mass flux & $10-30 \mathrm{~kg} /\left(\mathrm{m}^{2} \cdot \mathrm{s}\right)$ & $\pm 3.8 \%$ \\
\hline Heat flux & $3-10 \mathrm{~kW} / \mathrm{m}^{2}$ & $\pm 3.7 \%$ \\
\hline Vapor quality & $0.07-0.82$ & $\pm 5.4 \%$ \\
\hline Heat transfer coefficient & $0.72-8.82 \mathrm{~kW} /\left(\mathrm{m}^{2} \cdot \mathrm{K}\right)$ & $\pm 14.4 \%$ \\
\hline
\end{tabular}

880 